\title{
Children's Prepared and Unprepared Lies: Can Adults See Through Their Strategies?
}

\author{
LEIF A. STRÖMWALL*, PÄR ANDERS GRANHAG and \\ SARA LANDSTRÖM \\ Department of Psychology, Göteborg University, Sweden
}

\begin{abstract}
SUMMARY
We investigated adults' ability to detect children's prepared and unprepared lies and truths. Furthermore, we examined children's strategies when lying. Thirty children (11-13 years) were interviewed about one self-experienced and one invented event each. Half had prepared their statements, the other half not. Sixty adult observers assessed the veracity of 10 videotaped statements each. Overall deception detection accuracy $(51.5 \%)$ was not better than chance. The adults showed higher accuracy for unprepared statements (56.6\%), than prepared statements $(46.1 \%)$. The adults reported to have used more verbal than nonverbal cues to deception, especially the Detail criterion. The most frequent verbal strategy reported by the children was to use real-life components (e.g. own or others' experiences); the most frequent nonverbal strategy was to stay calm. Arguably, the low accuracy is due to adults' failure to see through the lying children's strategies. Copyright (C) 2006 John Wiley \& Sons, Ltd.
\end{abstract}

Do you believe a child that comes home with a scratched knee saying he or she fell off the bike? Most of us would probably not challenge that explanation and instead focus on cleaning up the wound. But what if the child had done something forbidden and decided to lie-would he or she get away with it? What strategies would the child use? What strategies or cues would the adult use when assessing the child's statement? Would the lie be easier to detect if it was unprepared? Questions like these were the starting point of the current study.

\section{DECEPTION DETECTION}

For almost 40 years, scholars have examined aspects of human deception and decoding of deception. Nonverbal differences between truth tellers and liars, verbal correlates of deception and psychophysiological techniques have all received considerable research interest (see Granhag \& Strömwall, 2004, for a recent update).

*Correspondence to: L. A. Strömwall, Department of Psychology, Göteborg University, P.O. Box 500, SE 40530 Göteborg, Sweden.

E-mail: leif.stromwall@psy.gu.se

Copyright (C) 2006 John Wiley \& Sons, Ltd. 
Much effort has been invested in human ability to detect deception, and which factors moderate the accuracy of veracity judgements (Bond and DePaulo, 2006 Vrij, 2000). In the latest meta-analysis on adults judging the veracity of other adults, the accuracy was found to be just above the level of chance: 54\% (Bond \& DePaulo, 2006). Furthermore, a truth bias has been found, that is participants make more judgements of truth than of deception (Bond \& DePaulo, 2006; Vrij, 2000).

\section{CHILDREN'S DECEPTION AND ADULTS'ACCURACY}

Research has shown that even young children, at the age of 4, are able to consciously construct and tell lies (Newton, Reddy, \& Bull, 2000). As children develop, they achieve a greater understanding of others' mental states and hence become better equipped at successful lying (Leekam, 1992). A children and deception research overview, including developmental aspects, was provided by Vrij (2002), and for another detailed description of developmental aspects of children's deception, see Lewis (1993).

Adults' ability to detect children's deception has been examined in a handful of studies. Feldman and colleagues published early studies and found that older children's deception were harder to detect than younger children's (e.g. Feldman, Jenkins, \& Popoola, 1979; Feldman \& White, 1980). Later research shows that adults are not very good at detecting children's deception (see Vrij, 2002, for a review). In one study, in which children lied about visiting a museum, the accuracy level was 59\% (Westcott, Davies, \& Clifford, 1991). In a study by Jackson and Granhag (1997), where children lied about watching a film, the adults' accuracy was at chance level. In both studies, the truths were more often correctly identified than the lies. These findings suggest a truth bias on behalf of the adults. In a study by Chahal and Cassidy (1995), children lied about the major events of a film, and the accuracy of lay persons (college students) was compared with that of teachers and social workers. No difference between those with daily work experience with children and those without such experience was found. Lewis, Stanger, and Sullivan (1989) found that adults could not discriminate liars from truth tellers when children were told not to peek at a forbidden object (see Talwar \& Lee, 2002, for a replication). In a study by Strömwall and Granhag (2005), children lied about watching a live performance by a magician, and the adults' deception detection accuracy was $59 \%$. Following previous studies, a significant truth bias was found.

Regarding the subjective cues to children's deception, previous research has shown that adults tend to use more verbal (e.g. details, consistency) than nonverbal (i.e. body movements, eye contact) cues when assessing the veracity of children's statements (e.g. Landström, Granhag, \& Hartwig, 2005; Landström, Granhag, \& Hartwig, in press). For example, in the study by Westcott et al. (1991), verbal cues (what the child said) were more frequently reported than nonverbal cues. In the Strömwall and Granhag (2005) study, examining the judgements of repeatedly interviewed lying and truth-telling children, the preference for verbal cues was even more evident. In that study, the consistency between each child's two statements was the most often reported cue used to make veracity judgements. Speculatively, when trying to detect a fabrication-type of lie about selfexperienced events, the observers pay attention to the verbal content, unlike when asked to detect children's deception about plainly denying having done something forbidden. In these latter cases, there are very small chances of paying attention to verbal content, as the lie may just consist of 'No, I didn't do that'. Another reason for adult observers' focusing 
on verbal content may be that they simply do not trust a child's nonverbal behaviour to be indicative of either truth or lie.

\section{PREPARED LIES AND TRUTHS}

Common sense might predict prepared lies to be harder to detect than unprepared ones, since the prepared liar can think through the content and details of the statement and for example, not contradict himself (Vrij, 2000). The prepared lie should be easier to tell, which in turn ought to be evident in fewer behavioural signs of 'thinking hard'. Research has supported this line of reasoning: a shorter latency period (DePaulo et al., 2003; Sporer \& Schwandt, 2006) and a faster speech rate (Vrij, 2000) has been found for prepared lies. These behaviours are in line with the attempted control approach, which suggests that a liar tries to control his or her behaviour in order to not leak deceptive signals (e.g. Vrij, 2000). However, a truth teller who has prepared his statements will show this behavioural pattern too (e.g. DePaulo, Lanier, \& Davies, 1983), making the task difficult for those who try to distinguish truths and lies. In the meta-analysis by Bond and DePaulo (2006), it is concluded that prepared messages appear more truthful than unprepared (when the same person has given both types of statements). A somewhat conflicting result is found when comparing between-subjects: prepared messages then appear less honest than spontaneous messages.

The deception detection accuracy of adults' prepared and unprepared lies and truths has been found to be in line with the common sense reasoning; it is easier to discriminate lies and truths when the statement is unprepared (Bond \& DePaulo, 2006).

\section{THIS STUDY}

This study was designed with two goals in mind: First, to examine the effect of the preparation factor on adults' ability to detect children's lies and truths. We know of no published studies on prepared and unprepared children and how accurate adults are at distinguishing between prepared lies and truths, and unprepared lies and truths. We chose to let the children lie and tell the truth about quite emotionally charged events that may happen to more or less all children. We argue that the ecological validity of the study is, therefore, higher than if we had chosen a more traditional paradigm (see Vrij, 2002). Furthermore, the study is not about coaching, an adult actively instructed a child to tell a certain story. The children in our study were allowed to themselves decide what to say and how to say it.

The second goal was to try to gain some insight into which strategies the children decided to use in order to try to make a truthful impression when lying. In previous research, it has been pointed out that we know too little about lying and truth-telling children's strategies (Lewis, 1993), and we therefore decided to make this an exploratory part of our study. Research has tried to infer what the child is thinking by observing its behaviour, but 'this type of evidence can never substitute for a verbal report' (Lewis, p. 104). In our study, the children provided verbal reports on both their verbal and nonverbal lie-telling strategies. We therefore chose children aged 11-13 years, since we needed children old enough to both understand and complete the deception task as well as to think back and write down their strategies. 


\section{PREDICTIONS}

We set up four predictions to be tested. We expected that:

1. Overall deception detection accuracy would be in line with previous research, that is, just above the level of chance (Vrij, 2002; Strömwall \& Granhag, 2005),

2. Deception detection accuracy would be higher for prepared statements than for unprepared statements (Bond \& DePaulo, 2006),

3. A truth bias would be found in the veracity judgements, leading to higher accuracy for truths than lies (Bond \& DePaulo, 2006; Strömwall \& Granhag, 2005),

4. The observers' self-reported justifications of their veracity judgements (i.e. their subjective cues to deception) would include more verbal than nonverbal cues (Landström et al., 2005; Landström et al., in press; Strömwall \& Granhag, in press; Westcott et al., 1991).

\section{METHOD}

\section{Phase 1: The children}

\section{Participants}

Thirty children (19 girls and 11 boys, aged 11-13 years) participated in this study. The children were recruited from local schools (in Gothenburg, Sweden) and we collected consent from parents and teachers.

\section{Procedure}

All children initially answered a Life Event Inventory questionnaire on paper (see Appendix 1). The Inventory was especially designed for this study, with the objective of including age-appropriate events (that children of this age group could have experienced) that would be emotionally charging (so the events would be remembered fairly well). Each child worked through the 13 items, answering each question with either 'yes' or 'no'. The children were thereafter randomly divided in two groups. One group (henceforth 'the prepared children') were instructed that they in a while would be interviewed about two of the events in the questionnaire; one that they had experienced and one that they had not. The children were instructed to talk about the not-experienced event as if it had really happened. For example, one child could be told that he or she would be expected to tell about when s/he found a dead bird (self-experienced event, truthful) and when s/he was bitten by a dog (not self-experienced, deceptive). This group of children was given a couple of minutes $\left(7^{1}\right)$ to prepare before being interviewed.

The other group of children (henceforth 'the unprepared children') was, just like the prepared children, informed that they were to be interviewed about two events from the form (one that they had experienced and one that they had not). However, unlike the prepared children, the unprepared children did not receive any information about which two events they were to be interviewed. The children were informed that the interviewer would tell them which events they were to talk about. All children were informed — one by

\footnotetext{
${ }^{1}$ We chose 7 minutes because the children needed time to prepare their lies and truths, and the experimenters needed a few minutes to get organised.
} 
one - that participation was voluntary and that they were free to abort participation. Only one child (a girl) did not want to lie; she was only interviewed about a truthful event.

All children were interviewed about one experienced and one nonexperienced event. The experimenter had randomly selected the events that the interviewer was to ask the child about from the Life Event Inventory. Four female interviewers with experience in interviewing children conducted the interviews. They were all blind to the condition (i.e. for any given event they did not know if the child was lying or telling the truth, was prepared or unprepared). All interviews were videotaped; the tapes showed the child and not the interviewer.

All interviews started out with the children being informed which event they were to talk about and received a few seconds to think about their statement. This was included in order to not make the task too difficult for the unprepared children. The interviewer followed a standardised procedure and all children were given the same amount of time (4-6 seconds) to think about their statement. The procedure was as follows: the interviewer first posed the question 'can you tell me about [one of the events],' and before the child was able to answer the interviewer said: 'wait just a second, I am just going to close the door.' Before the next statement, the interviewer delayed the child's answer by saying 'wait just a second before answering, I am just going to make sure that the camera is still running.' See Appendix 2 for a full list of the interview questions.

\section{The children's ratings and strategies}

After the interview, the children were given a questionnaire to fill out. The questionnaire consisted of five items; four in which the children were asked to, on a five point scale ranging from 1 (no, not at all) to 5 (yes, very much) how nervous and how difficult they thought it had been to be interviewed about the experienced and the nonexperienced event, respectively. The fifth item was an open-ended question in which children were asked to write down the strategy or strategies they had used to be successful in lying.

After the strategies had been verbatim transcribed, two coders conducted a content analysis using data-driven categorisations. First, the coders categorised the responses as either verbal (strategies concerning the verbal content) or nonverbal (strategies concerning the nonverbal behaviour). For the verbal strategies, the following five categories emanated: Own experiences: The child used as a starting point something real that had happened and added elements that were untrue. Others experiences: The child talked about events they had heard others (siblings, friends) describe. Details: The child used lots of details in his/ her story. Credibility: The child tried to make the story sound credible, for example by using more proper language. Don't remember: The child said, 'I was young when this happened and I don't remember the details.'

The nonverbal strategies were the following: Stay calm: The child tried to stay calm. Act normal: The child tried to look and act normal. Not laugh: The child tried not to laugh when telling a lie. Gaze: The child looked in the interviewers' eyes or in the camera. Different behaviour: The child reported things that s/he had done differently when lying in comparison to when s/he was telling the truth.

\section{Inter-rater reliability}

Two persons coded the children's strategies. The level of agreement between the two coders was $91.3 \%$. That is, 42 of the 46 strategies (verbal and nonverbal) were coded into the same categories by both coders. Disagreements were resolved in a conference between the two coders. 


\section{Phase 2: The observers}

\section{Participants}

A total of 60 undergraduate students from Göteborg University (40 women, 20 men) participated as observers. Their age ranged from 18 to 52 years $(M=26.28, S D=5.66)$. The participants were guaranteed a payment of an equivalence of 25 SEK (approximately 3 USD) and they were told that if they managed to make eight or nine correct veracity judgements, they would receive an additional 25 SEK. If they managed to make all 10 correct veracity judgements, they would receive 75 SEK (approximately 10 USD).

\section{Design}

A 2 (Veracity status: truthful vs. deceptive) $\times 2$ (Statement: prepared vs. unprepared) within-group design was employed.

\section{Materials and procedure}

The 30 children all gave two statements, one truthful and one deceptive. These 60 statements were edited onto 6 videotapes. Each tape showed 10 interviews with 10 different children, 5 deceptive and 5 truthful. It was further made sure that at least two interviews of each type (prepared and unprepared truths and lies) were included on each videotape. $^{2}$

The observers watched the videotapes in groups of up to 10 persons, supervised by an experimenter. The observers were informed, prior to watching the videotape, that they were going to watch interviews with 10 children and after each interview assess the veracity of that statement. The instructions stated that the tape consisted of approximately half each of lies and truths (but not that the distribution was exactly 50-50). The observers were also informed that the children had filled out a Life Event Inventory questionnaire and then been requested to talk about one event they had experienced and one they had not. The observers were not informed that some of the children had prepared their statements and that others had not. After each interview, the experimenter paused the videotape for 2 minutes to give the observers time to fill out the questionnaire. The observers were not allowed to make any changes in previous judgements. The total time varied from 45 minutes to 1 hour.

\section{Questionnaire}

Before watching the videotape the observers answered questions about their sex and age. After each video clip, the observers were asked to make a dichotomous truth/lie judgement, after which the observers were asked to rate (on a 10-point scale) how confident they were that this veracity judgement was correct from 1 (completely unsure) to 10 (absolutely sure). Furthermore, the observers were asked to write down the most important cue that they had used when assessing each child's veracity.

\section{Cues to deception and truth}

Two persons coded $20 \%$ of the observers' self-reported cues for assessing veracity. The percentage of agreement between the two coders was $80.1 \%$. Disagreements were resolved

\footnotetext{
${ }^{2}$ Tapes A and E consisted of two prepared truths, three unprepared truths, three prepared lies and two unprepared lies. Tapes B and D consisted of three prepared truths, two unprepared truths, two prepared lies and three unprepared lies. Tapes $\mathrm{C}$ and $\mathrm{F}$ consisted of two prepared truths, three unprepared truths, two prepared lies and three unprepared lies. A one-way ANOVA showed that the six tapes were not significantly different in difficulty, $F(5,54)=2.27, p>0.05$.
} 
in a conference between the two coders. Subsequently, one of the coders coded the remaining cues. The observers reported a total of 838 cues to justify their deceptive and truthful judgements.

\section{RESULTS}

\section{The observers}

\section{Veracity assessments}

Overall, $51.5 \%(S D=17.15)$ of the veracity assessments were correct; this was not different from the level of chance, one-sample $t(59)=0.68, p=0.50$, and was in line with our first prediction. The range in participant correctness was quite large, from 20 to $90 \%$.

For each participant, an accuracy score was calculated for each type of statement judged: prepared truths and lies, and unprepared truths and lies. A 2 (Veracity status: truthful vs. deceptive) $\times 2$ (Type of statement: prepared vs. unprepared) repeated-measures ANOVA was conducted. The main effect for Veracity status was significant, $F(1,59)=8.31$, $p<0.01, \eta^{2}=0.12$, with $55.0 \%$ correct judgements for truthful statements and $47.6 \%$ correct judgements for deceptive statements, thereby supporting prediction 3 .

As further predicted, a significant main effect for Type of statement was found, $F(1,59)=5.72, p<0.05, \eta^{2}=0.09$ : unprepared statements were identified with higher accuracy $(56.6 \%)$, than prepared statements $(46.1 \%)$. The Veracity $\times$ Type of statement interaction effect was not significant, $F(1,59)=0.006, p=0.94$. See Table 1 for mean values.

\section{Response bias}

The observers stated this child is telling the truth $(M=53.5 \%, S D=9.17)$ more often than this child is lying $(M=46.5 \%, S D=9.17)$. A paired-samples $t$-test revealed this difference to be significant, $t(59)=2.96, p=0.004$, supporting our prediction of a truth bias. Subsequent analyses did not show any significant differences in response distribution as a function of the statements being prepared or unprepared, although the difference between unprepared (50\% lie judgements) and prepared statements (42.6\% lie judgements) was close: paired-samples $t(59)=1.90, p=0.06$.

\section{Confidence}

The observers' overall mean confidence in the correctness of their veracity judgements was $5.94(S D=1.21$, scale from 1 to 10$)$. The accuracy/confidence correlation was $r=0.07$, $p=0.61$, indicating that the participants could not realistically assign confidence to their veracity judgements. Additional analyses showed that participants were significantly more

Table 1. Accuracy percentages by preparation and veracity

\begin{tabular}{lccccc}
\hline & \multicolumn{3}{c}{ Prepared } & & \multicolumn{2}{c}{ Unprepared } \\
\cline { 2 - 3 } \cline { 5 - 6 } Veracity & $M$ & $S D$ & & $M$ & $S D$ \\
\hline Truthful & 50.00 & 45.44 & & 60.00 & 31.03 \\
Deceptive & 42.14 & 32.04 & & 53.12 & 31.10 \\
\hline
\end{tabular}


confident in their truth-judgements $(M=6.21, S D=1.48)$ than in their lie-judgements $(M=5.59, S D=1.37), t(59)=3.26, p<0.01$.

\section{Adults' cues to deception}

As predicted, the observers reported the using of more verbal than nonverbal cues when making their veracity judgements, 574 verbal and 264 nonverbal cues, $\chi^{2}(1$, $N=838)=114.68, p<0.001$. See Table 2 for all self-reported cues.

The most often reported cue was Details (rich or poor in detail), making up 190 (or $33.1 \%)$ of the 574 verbal cues. Other frequently reported cues were Confidence ( $N=110$; how confident/unconfident the child seemed), Plausibility ( $N=89$; plausible or implausible story) and Nervous $(N=80$; whether the child appeared nervous or not).

We tested, with two-way Chi-square tests, the distribution of the cues for correct and incorrect judgements over prepared and unprepared children. The distribution of Details was significantly different from what could be expected from chance, $\chi^{2}(1$, $N=190)=4.68, p<0.05$. An inspection of the cell frequencies indicated that observers who used the Details cue made more correct (than incorrect) assessments of unprepared statements, but more incorrect (than correct) assessments of prepared statements. Similar patterns were found for Latency, $\chi^{2}(1, N=34)=5.67, p<0.05$, and Nervous $\chi^{2}(1$, $N=80)=9.28, p<0.01$. That is, observers who used these cues made more correct assessments of unprepared statements, but more incorrect assessments of prepared statements.

Table 2. Frequencies of self-reported cues justifying correct and incorrect judgements of prepared and unprepared statements

\begin{tabular}{lrrrrrr}
\hline & \multicolumn{2}{c}{ Prepared } & & \multicolumn{2}{c}{ Unprepared } & \\
\cline { 2 - 3 } Cue category & Correct & Incorrect & & Correct & Incorrect & $N$ \\
\hline Verbal & & & & & \\
$\quad$ Details & 38 & 51 & & 59 & 42 & 190 \\
Confidence & 26 & 22 & & 34 & 28 & 110 \\
Plausibility & 17 & 16 & & 31 & 25 & 89 \\
Rehearsed & 12 & 7 & & 16 & 18 & 53 \\
Clarity & 10 & 6 & & 13 & 9 & 38 \\
Consistency & 9 & 7 & & 8 & 13 & 37 \\
Latency & 6 & 10 & & 14 & 4 & 34 \\
Completeness & 7 & 8 & & 6 & 2 & 23 \\
Total & 125 & 127 & & 181 & 141 & 574 \\
Nonverbal & & & & & \\
$\quad$ Nervous & 21 & 25 & & 27 & 7 & 80 \\
Credibility & 10 & 17 & & 12 & 13 & 52 \\
Body movements & 16 & 10 & & 11 & 9 & 46 \\
Gaze & 15 & 11 & & 7 & 4 & 37 \\
Smiling, laughing & 7 & 6 & & 14 & 8 & 35 \\
Confident appearance & 4 & 2 & & 2 & 6 & 14 \\
Total & 73 & 71 & & 73 & 47 & 264 \\
\hline
\end{tabular}

Notes: All cues are bi-directional. ${ }^{*}=p<0.05,{ }^{* *}=p<0.01$. 
Table 3. The percentage of children's self-reported strategies used when telling lies by prepared and unprepared children

\begin{tabular}{|c|c|c|c|c|}
\hline \multirow{3}{*}{$\frac{\text { Strategy }}{\text { Verbal }}$} & \multicolumn{4}{|c|}{ Children } \\
\hline & \multicolumn{2}{|c|}{ Prepared } & \multicolumn{2}{|c|}{ Unprepared } \\
\hline & 40.00 & (8) & 57.69 & (15) \\
\hline Own experiences & 20.00 & (4) & 7.70 & (2) \\
\hline Others' experiences & 10.00 & (2) & 15.38 & (4) \\
\hline Details & 10.00 & (2) & 15.38 & (4) \\
\hline Credibility & - & - & 15.38 & (4) \\
\hline Don't remember & - & - & 3.85 & (1) \\
\hline Nonverbal & 60.00 & (12) & 42.31 & (11) \\
\hline Stay calm & 25.00 & (5) & 19.23 & (5) \\
\hline Look normal & 5.00 & (1) & 3.85 & (1) \\
\hline Not laugh & - & - & 15.38 & (4) \\
\hline Gaze & 15.00 & (3) & - & - \\
\hline Different behaviour & 15.00 & (3) & 3.85 & (1) \\
\hline Total & 100.00 & (20) & 100.00 & (26) \\
\hline
\end{tabular}

Note: Each child could give more than one strategy; therefore the differences between unprepared and prepared in total number of strategies. Frequencies in parentheses.

\section{The children}

The children's lie-telling strategies

Our exploration of the liars' strategies showed, on a general level, that the children reported to have used many different strategies: of the in total 46 strategies indicated, 10 different categories were found. Looking at the raw frequencies, prepared children seem to favour nonverbal strategies over verbal strategies, and unprepared children reported the opposite pattern. However, this raw frequency variation did not reach statistical significance, $\chi^{2}(1)=1.41, p>0.05$. The most frequently reported (disregarding the prepared/ unprepared distinction) verbal strategies were to use Own or Other's experiences or to add Details, and the most common nonverbal strategy was to Stay calm. All strategies used when telling lies broken down for prepared and unprepared children are presented in Table 3. To find out if children using different strategies were judged differently, we compared the mean number of lie judgements from the adult participants for verbal (48.2\%) and nonverbal (44.3\%) strategy children. The difference was not significant, $t(23)=0.44, p>0.05$, suggesting that whether a child chooses a nonverbal or verbal strategy did not matter in terms of how its lie was perceived. ${ }^{3}$

\section{Children's ratings}

The children rated how nervous they were while telling the truth and while lying, and how demanding it was to be interviewed about the truth and the lie, respectively, on 1 (not at all) to 5 (very much) scales. Comparing prepared and unprepared children, we found no differences for any of the variables, $p$ 's $=0.08$ or larger.

Comparing within-subjects, the children showed a tendency to be more nervous when lying $(M=2.92, S D=1.06)$ than when telling the truth $(M=2.42, S D=0.99)$, however

\footnotetext{
${ }^{3}$ Since there were only 30 children (and a few of them did not answer the strategy item), the total number is too low to make a more detailed analysis, for example if those children who used the eye contact strategy were more often judged as truth tellers.
} 
not significant, paired-samples $t(25)=1.76, p=0.09$. A significant difference was found for how demanding it was to lie $(M=2.26, S D=1.02)$ compared to telling the truth $(M=1.78, S D=0.89)$, paired-samples $t(26)=2.23, p=0.04$. Note, however, that the rather low mean values indicate that the children found neither task very demanding.

\section{DISCUSSION}

\section{Deception detection}

In general, the adult participants were not very good at detecting the children's deception. The overall accuracy was, as expected, not different from the level of chance. Looking at detection rates for truthful and deceptive statements separately, a significant veracity effect emerged. The truths were more often correctly identified than lies, as found in several previous studies (Vrij, 2002). This can, at least in part, be explained by the participants' truth bias, that is they made more truth judgements than lie judgements. We predicted and found this bias to be significant, which supports previous findings (e.g. Westcott, Davies, \& Clifford, 1991; Strömwall \& Granhag, in press).

The main result was that we found support for our predicted effect of preparation: adults' accuracy for unprepared statements was higher than for prepared ones. This finding is in line with Bond and DePaulo (2006), albeit their meta-analysis included adult senders of the prepared and unprepared messages. In this study, we show that the effect of preparing the statement before being interviewed hold true also for 11 to 13 -year-old children. However, the observed effect size of the difference was not large, and neither was it in the Bond and DePaulo meta-analysis. It seems safe to say that variation in preparation affects the senders' behaviour and verbal content to some degree, but not to such an extent that their unprepared lies are easily detected.

With respect to the adult's self-reported cues to deception and truth, perhaps the most striking finding was the large number of different cues they claimed to have used in making their veracity assessments, indicating miscellaneous ideas about what are cues to deception. Based on previous research (e.g. Landström et al., in press), we predicted and found the use of more verbal than nonverbal cues. Judging from the cues that the adults reported, they foremost search for richness of detail when asked to assess veracity in an experimental setting like this. Analyses of real-life cases show that professionals in a forensic context use the amount of detail as a cue to deception and truth (Schelin, 2006). Richness of detail is furthermore included in the Criteria-Based Content Analysis as a truth criterion (Köhnken, 2004). The novice lie catchers in our study hence mirror the 'professional' use of the Detail cue.

Our analysis showed that the observers using the Detail cue made more correct (than incorrect) assessments of unprepared statements, but more incorrect (than correct) assessments of prepared statements. This suggests that the Detail cue is of limited diagnostic value (it works to some extent for unprepared statements, but not for prepared). It seems as unprepared liars were not fully successful in filling out their statements with detailed information, but that prepared liars were successful in incorporating enough details to make the adults assess their statements as truthful.

A similar pattern emerged from our analysis of the Nervous cue. Observers who used their perceived nervousness of the child as the base for their veracity assessments reached different levels of correctness depending on if the child delivered a prepared or 
unprepared statement. Specifying this interaction: lying and truth-telling prepared children seemed to have appeared equally nervous, whereas unprepared liars seemed to have appeared more nervous than unprepared truth-tellers (showing that this cue may be of some, but still limited, diagnostic value). In summary, our cue analysis gave some insight into the adults' reasoning when making veracity assessments, and from this we can at least partly understand the low overall accuracy.

\section{Children's strategies}

One goal of the study was to begin exploring children's strategies when telling prepared and unprepared lies, which previous research has not studied. We found a (nonsignificant) tendency for prepared children to report the use of more nonverbal strategies and unprepared children to report the use of more verbal strategies. Had we had a bigger sample, this might have been significant.

From an individual differences standpoint, it is interesting to note the diversity of strategies: some children focused on controlling their nonverbal behaviour, some on inventing a story, some on altering a truthful event. Future research will no doubt shed more light on children's strategies when attempting to lie to adults.

Our analysis of the children's strategies suggests one pattern for the verbal strategies and one pattern for the nonverbal strategies. For the verbal strategies, the common denominator seems to be to 'use ingredients from real life' (either own or others' experiences) to compose the lie; for the nonverbal strategies, the common denominator seems to be to 'act in a calm and controlled manner'. Interestingly, these findings are in line with the most common verbal and nonverbal strategies reported by adult liars; that is trying to produce a detailed statement and trying to stay calm (Hartwig, Granhag, \& Strömwall, in press).

One might argue that a deceptive child focusing on controlling the verbal content might be differently assessed than a deceptive child focusing on controlling his/her nonverbal behaviour, but we found no support for such reasoning. We found no remarkable results in terms of verbal strategy children being more or less often correctly assessed than nonverbal strategy children. It seems as whether a child chooses a nonverbal or verbal strategy does not have an impact on adults' accuracy, indicating misconceptions about both verbal and nonverbal cues to deception on the part of the adults.

\section{Limitations and future research}

One possible limitation of this work is that the children were not very nervous and did not find the task very demanding in general (according to the self-reports). However, if the children had been completely at ease, we probably would not have found the significant differences for neither the veracity nor the preparation factors. It would be interesting to investigate adults' accuracy in detecting messages from children more nervous than in the present study; this however demands more pressure put on the children, which would be questionable from an ethical viewpoint. Our study has one advantage in including children telling the truth and lying about ecologically valid events, not a more contrived laboratory event. From the nervous and demanding standpoint, however, the events used might have contributed to less nervousness than when children are asked to tell a lie about unfamiliar events.

It should also be noted that all children in the current study fabricated that they had experienced an event which they in fact had not, in real life it might be that children more 
often falsely deny having committed some kind of transgression (e.g. a theft). Hence, an important future research objective is to investigate adult's ability to separate truthful and false denials.

Other limitations are the sample size and age group. Thirty children, all from the same age group are obviously not enough for a proper understanding of children's deceptive strategies. Developmental aspects need to be investigated with data from several age groups to determine when children's thinking processes has reached enough maturity to successfully lying to adults. In addition to expanding on the present study in these aspects, further research should also investigate children's truth-telling strategies to make comparisons possible.

On a methodological note, this study relied quite heavily on self-reports. Any study using this method is susceptible to demand characteristics and the limited human ability to accurately report the true reasons for their behaviour. One reason why we chose children aged 11-13 years was that they — at least in theory — should be able to understand the task, and to provide answers to self-reports almost at levels with adults. There is, however, no specific reason to suspect that the children were anything but truthful when they gave their answers in our study. Future research might try to use indirect measures of, for example, the children's lie-telling strategies, which would make for an interesting comparison to our data.

\section{CONCLUSIONS AND APPLIED IMPLICATIONS}

To correctly assess a child's statement is important in many different situations. Whether investigating alleged criminal acts towards children, or acts allegedly committed by minors, adults face the task of separating lies from truths (Davies, 2004). The current results underline that this is a very difficult task: adults' overall deception detection performance was no better than expected by chance alone. Adding the previously overlooked aspect of preparation, we showed that the prepared statements were more difficult to detect than were the unprepared statements. In fact, the adults' accuracy for prepared statements was only $46.1 \%$.

We also began the investigation of children's strategies when lying. On a general level, our analysis showed that the common goal of the verbal strategies was to use bits and pieces from real life in order to tell a convincing story and that the common goal of the nonverbal strategies was to act in a calm and controlled manner, adding support to the attempted control approach (Vrij, 2000). Contrasting the pattern found for the children's strategies and the adult's most frequently reported verbal and nonverbal subjective cues to deception (i.e. lack of detail and nervousness), provides a probable part explanation for the poor deception detection performance.

Translating our findings to applied settings, we suggest the following: First, it should be acknowledged that detecting deception in children is a difficult task, perhaps as difficult as detecting adults' lies. Second, it might be useful to consider whether the statement to be assessed is prepared or unprepared (this could be established by a close investigation of the case-file), and if it is prepared there are several reasons to be extra cautious. Specifically, for these situations (i.e. prepared statements), it might pay off to refer from using the Detail criterion (we found that using this criterion resulted in more incorrect than correct assessments), and drawing strong conclusions based on whether the child acted in a nervous manner (we found that using this criterion resulted in more incorrect than correct assessments). Third, even if the child being questioned is unprepared, adults' need to be 
very cautious when assessing veracity. Our study suggests that children may need just a few seconds to deliver a lie difficult to distinguish from the truth. Hence, to pose a surprising question in order to try to catch a child off guard, is no guarantee that lying (or for that matter truth telling) will 'shine through'. A liar's instant evoking of subtle verbal strategies may hinder the lie from shining through, and a truth teller might very well experience memory problems that may hinder the truth from shining through.

Finally, our results show that adults have very few reasons to be smug about their ability to detect deception in 11- to 13-year-old children. Our title asked whether adults' can see through lying children and their strategies, and the answer seems to be 'no, they cannot'. This worrying reply is not only explained by the fact that lying children apparently use strategies to convince the adults, but also by the adults' misconceptions about children's verbal and nonverbal behaviour (see e.g. Vrij, Akehurst, \& Knight, 2006). Speculatively, lying children are successful at counter-acting the lie-catching strategies used by adults, whereas many adults fail seeing through the lie-telling strategies used by children.

\section{ACKNOWLEDGEMENTS}

This research was sponsored by a post doc grant given to the first author by The Swedish Council for Working Life and Social Research. A part of this research was presented at the 15th European Conference on Psychology and Law in Vilnius, Lithuania, July 2005. Thanks to Emma Roos af Hjelmsäter and Lina Leander for help with data collection and codings. Special thanks to all children who participated.

\section{REFERENCES}

Bond, C. F., Jr., \& DePaulo, B. M. (2006). Accuracy of deception judgements. Personality and Social Psychology Review, 10, 214-234.

Chahal, K., \& Cassidy, T. (1995). Deception and its detection in children: a study of adult accuracy. Psychology, Crime \& Law, 1, 237-245.

Davies, G. M. (2004). Coping with suggestion and deception in children's accounts. In P. A. Granhag, \& L. A. Strömwall (Eds.), The detection of deception in forensic contexts (pp. 148-171). Cambridge, UK: Cambridge University Press.

DePaulo, B. M., Lanier, K., \& Davies, T. (1983). Detecting the deceit of the motivated liar. Journal of Personality and Social Psychology, 45, 1096-1103.

DePaulo, B. M., Lindsay, J. L., Malone, B. E., Muhlenbruck, L., Charlton, K., \& Cooper, H. (2003). Cues to deception. Psychological Bulletin, 129, 74-118.

Feldman, R. S., Jenkins, L., \& Popoola, O. (1979). Detection of deception in adults and children via facial expressions. Child development, 50, 350-355.

Feldman, R. S., \& White, J. B. (1980). Detecting deception in children. Journal of Communication, $30,121-128$.

Granhag, P. A., \& Strömwall, L. A. (Eds.). (2004). The detection of deception in forensic contexts. Cambridge, UK: Cambridge University Press.

Hartwig, M., Granhag, P. A., \& Strömwall, L. A. (in press) Guilty and innocent suspects' strategies during police interrogations. Psychology, Crime and Law.

Jackson, J. L., \& Granhag, P. A. (1997). Truth or fantasy: The ability of barristers and laypersons to detect deception in children's testimony. In J. F. Nijboer, \& J. M. Reintjes (Eds.), New trends in criminal investigation and evidence (pp. 213-220). Lelystad, The Netherlands: Koninklijke Vermande. 
Köhnken, G. (2004). Statement validity analysis and the 'detection of the truth'. In P. A. Granhag, \& L. A. Strömwall (Eds.), The detection of deception in forensic contexts (pp. 41-63). Cambridge: Cambridge University Press.

Landström, S., Granhag, P. A., \& Hartwig, M. (2005). Witnesses appearing live versus on video: effects on observers' perception, veracity assessments and memory. Applied Cognitive Psychology, 19, 913-933. DOI: 10.1002/acp.1131

Landström, S., Granhag, P. A., \& Hartwig, M. (in press). Children's live and videotaped testimonies: How presentation mode affects observers' perception, assessment and memory. Legal and Criminological Psychology.

Leekam, S. R. (1992). Believing and deceiving: Steps to becoming a good liar. In S. J. Ceci, M. DeSimone Leichtman, \& M. Putnick (Eds.), Cognitive and social factors in early deception (pp. 47-62). Hillsdale, NJ: Erlbaum.

Lewis, M. (1993). The development of deception. In M. Lewis, \& C. Saarni (Eds.), Lying and deception in everyday life (pp. 90-105). New York: Guilford Press.

Lewis, M., Stanger, C., \& Sullivan, M. W. (1989). Deception in 3-year-olds. Developmental Psychology, 25, 439-443.

Newton, P., Reddy, V., \& Bull, R. (2000). Children's everyday deception and performance on falsebelief tasks. British Journal of Developmental Psychology, 18, 297-317.

Schelin, L. (2006). Bevisvärdering av utsagor i brottmål (Evidence evaluation of statements in criminal cases) Unpublished Ph.D. thesis, Stockholm University, Sweden.

Sporer, S. L., \& Schwandt, B. (2006). Paraverbal indicators of deception: A meta-analythic synthesis. Applied Cognitive Psychology, 20, 421-446. DOI: 10.1002/acp.1190

Strömwall, L. A., \& Granhag, P. A. (2005). Children's repeated lies and truths: Effects on adults' judgements and reality monitoring scores. Psychiatry, Psychology and Law, 12, 345-356.

Strömwall, L. A., \& Granhag, P. A. (in press). Detecting deceit in pairs of children. Journal of Applied Social Psychology.

Talwar, V., \& Lee, K. (2002). Development of lying to conceal a transgression: Children's control of expressive behaviour during verbal deception. International Journal of Behavioral Development, 26, 436-444.

Vrij, A. (2000). Detecting lies and deceit. Chichester: John Wiley.

Vrij, A. (2002). Deception in children: a literature review and implications for children's testimony. In H. L. Westcott, G. M. Davies, R. H. C.Bull (Eds.), Children's testimony: A handbook of psychological research and forensic practice (pp. 175-194). Chichester: Wiley.

Vrij, A., Akehurst, L., \& Knight, S. (2006). Police officers', social workers', teachers' and the general public's beliefs about deception in children, adolescents and adults. Legal and Criminological Psychology, 11, 297-312.

Westcott, H. L., Davies, G. M., \& Clifford, B. R. (1991). Adults' perceptions of children's videotaped truthful and deceptive statements. Children \& Society, 5, 123-135.

\section{APPENDIX 1}

\section{Life Event Inventory}

1. Do you remember an occasion when you rode your bike, fell over and hurt yourself?

2. Do you remember an occasion when you were bitten by a dog?

3. Do you remember an occasion when you were scratched by a cat?

4. Do you remember an occasion when you were stung by a bee?

5. Do you remember an occasion when you had a tooth removed at the dentist?

6. Do you remember an occasion when you lost money?

7. Do you remember an occasion when you received a shot at the doctors?

8. Do you remember an occasion when you burnt your self on the stove?

9. Do you remember an occasion when you happened to break an ornament?

10. Do you remember an occasion when you found a dead bird? 
11. Do you remember an occasion when you squeezed a finger?

12. Do you remember an occasion when you sprained your ankle?

13. Do you remember an occasion when you tasted something nauseating?

All items had Yes/No as answer alternatives.

\section{APPENDIX 2}

These questions were put to the children during the interviews. All children (prepared and unprepared, deceptive and truthful) were asked the same questions.

The interviewers introduced themselves, asked the children to sit down and established rapport before starting the interviews.

1. Can you tell me about the time you .... [the interviewer filled in the event in question]

2. Anything else you remember?

3. Where did this happen?

4. Can you tell me anything more about the place where it happened?

5. How old were you when this happened?

6. Can you remember what time of day it was?

7. Were you alone? 